\title{
Modificações microclimáticas sob proteção de polipropileno cultivado com espécies hortícolas em Córdoba, Espanha ${ }^{1}$.
}

\author{
Rosana Fernandes Otto ${ }^{1}$; Carmen Gimenez ${ }^{2}$; Nicolás Castilla ${ }^{3}$. \\ ${ }^{1}$ UEPG - Depto. de Fitotecnia e Fitossanidade, Praça Santos Andrade s/n, 84.010-790, Ponta Grossa-PR; ${ }^{2}$ Universidad de Córdoba - \\ Depto. de Agronomia, Apdo. de Correos 3048, 14080, Córdoba, Espanha; ${ }^{3}$ CIDA - Depto. de Horticultura, Apdo. de Correos 2027, \\ 18080, Granada, Espanha. e.mail: srotto@convoy.com.br
}

\section{RESUMO}

A cobertura de plantas com o material "não tecido" de polipropileno constitui uma das técnicas mais recentes utilizada para proteção de cultivos hortícolas. Dentro deste tema, foram conduzidos quatro experimentos na área experimental do "Centro de Investigación y Desarrollo Agrario", em Córdoba, Espanha. Avaliou-se a amplitude das modificações das temperaturas do ar e do solo, da radiação fotossinteticamente ativa e o conseqüente efeito sobre a produção de couve-chinesa, beterraba, espinafre e alface cultivados sob proteção do "não tecido" de polipropileno (PP) e em ambiente natural (AN), durante a primavera, outono e inverno de 1995/1996. Utilizou-se delineamento experimental de blocos ao acaso com quatro repetições. As temperaturas do ar e do solo sob PP foram maiores que em $\mathrm{AN}$ na fase inicial de crescimento das espécies estudadas, com diferenças de até 5,5 e $2,2^{\circ} \mathrm{C}$ para temperaturas do ar e do solo, respectivamente. Entretanto, com o crescimento das culturas, os valores de temperatura do tratamento PP tenderam a se igualar ao tratamento $\mathrm{AN}$, tanto para temperatura do ar como do solo. Para couve chinesa e espinafre, a temperatura do ar sob PP foi até $3,1^{\circ} \mathrm{C}$ menor que a observada em condições naturais depois da metade e final do ciclo, respectivamente. Para couve-chinesa, beterraba e espinafre cultivados sob PP, as modificações do microclima favoreceram a maior precocidade e produção quando comparadas às plantas cultivadas em AN. Entretanto, para a cultura da alface o aumento das temperaturas do ar e solo sob $\mathrm{PP}$ em relação a $\mathrm{AN}$ não resultou em aumento da produção final. Neste caso, os baixos níveis de radiação incidente sob o "não tecido" e o prolongado período de precipitação ocorrido durante os meses de inverno interferiram negativamente sobre o crescimento da espécie, sendo recomendado a retirada da proteção de plantas nesta condição climática.

Palavras chave: Brassica pekinensis, Beta vulgaris, Lactuca sativa, Spinacia oleracea, couve-chinesa, beterraba, alface, espinafre, temperatura do solo, temperatura do ar, radiação, "não tecido", proteção de plantas, área foliar, biomassa vegetal.

\section{ABSTRACT}

Microclimatic modifications under polypropylene protection for horticultural crops in Córdoba, Spain.

Plants cover with a nonwoven polypropylene protection comprises one of the most recent techniques for protecting horticultural crops. Four experiments have been conducted at the experimental area of the "Centro de Investigación y Desarrollo Agrario" in Córdoba, Spain. The aim of this study was to evaluated the air and soil temperature amplitudes and the photosynthetically active radiation and its effects on the production of chinese cabbage, table beet, spinach and lettuce grown under nonwoven polypropylene protection (PP) and also at environment conditions (AN) during the spring, autumn and winter of 1995/1996. The experiments were carried out in a randomized blocks design with four replications. Air and soil temperatures under PP were higher than those ones at $\mathrm{AN}$ conditions during initial growth period for all studied species, with differences up to 5.5 and $2.2^{\circ} \mathrm{C}$ for air and soil temperature, respectively. However, with crops growth, temperature values under PP trended to be similar to AN for both air and soil. For chinese cabbage and spinach, air temperature under PP was lower than AN after middle and final cycle, respectively. For chinese cabbage and spinach, air temperature under PP was up to $3.1^{\circ} \mathrm{C}$ lower than the observed at $\mathrm{AN}$ condition after middle and final stage of the cycle, respectively. For chinese cabbage, table beet and spinach grown under PP, such microclimatic modifications have promoted a higher precocity and production compared to AN conditions. However, for lettuce crop the higher temperature under PP did not result in a higher final production. In this case, low incidence radiation levels under PP and also a prolonged precipitation period during the winter months interfered negatively with crops growth, where PP protection should be removed in this climatic conditions.

Keywords: Brassica pekinensis, Beta vulgaris, Lactuca sativa, Spinacia oleracea, chinese cabbage, table beet, lettuce, spinach, soil temperature, air temperature, radiation, nonwoven, plant protection, leaf area, vegetable biomass.

\section{(Aceito para publicação em 14 de agosto de 2.000)}

\begin{abstract}
A produção de espécies hortícolas pode estar limitada pelas condições climáticas de algumas regiões durante parte do ano. Nestes casos, o uso de técnicas de proteção de cultivos é uma alternativa para viabilizar a produção, possibilitando microclima favorável ao crescimento e ao desenvolvimento das
\end{abstract}

culturas sob esse ambiente. Diferentes estruturas e materiais podem ser utilizados para este fim, como exemplo, as estufas e túneis cobertos com polietileno, telas de "nylon", entre outros. A partir da década de 80, “" "não tecido" de polipropileno (PP) também passou a ser utilizado na agricultura como material para proteção de es- pécies hortícolas (Wells \& Loy, 1985; Hernández et al., 1996). Uma das vantagens do PP está na colocação direta sobre a planta ou solo semeado, não necessitando estruturas de sustentação para o material. Outra vantagem é a possibilidade de colocação e retirada em qualquer fase de crescimento da cultura.

\footnotetext{
${ }^{1}$ Parte da tese de doutorado do primeiro autor apresentada à "Universidad de Córdoba”, Espanha. Trabalho executado com apoio financeiro da Capes.
} 
A província de Córdoba (Espanha) apresenta condições climáticas favoráveis ao cultivo de hortaliças durante grande parte do ano, com exceção dos dias do alto verão e do inverno. Para a região, o uso do PP poderia ser uma alternativa interessante de cultivo protegido de hortaliças. A técnica permitiria a produção precoce com semeadura ou transplante no final do inverno e retirada do PP quando as condições ambientais fossem favoráveis. $\mathrm{O}$ mesmo poderia ocorrer nos cultivos de outono, onde o uso do PP sobre as plantas seria necessário somente na fase final do ciclo, quando as condições ambientais fossem desfavoráveis.

O conhecimento da amplitude das modificações microclimáticas que ocorre no ambiente protegido ao longo do ciclo de diferentes espécies e em diferentes épocas do ano ajudaria no correto manejo da técnica de proteção, permitindo projetar a produção em épocas mais adequadas. Sabe-se que, parte da energia que fica disponível a nível das culturas se dissipa como calor sensível, outra parte como calor latente e outra é consumida em processos metabólicos. Alguns estudos sobre este tema já foram realizados em estufas e túneis (Wolfe et al, 1989; Andrade Júnior, 1994; Lorenzo, 1994; Fernández et al., 1995), porém pouco se conhece sobre a amplitude das modificações microclimáticas devido ao uso do PP. A radiação solar incidente sobre a proteção de PP, como um componente do balanço de energia, é absorvida e reemitida como radiação térmica, sendo modificada pela transmissividade do material. Para o polipropileno de 17 g.m², a transmissividade está em torno de $80 \%$ (Wells \& Loy, 1985; Hernández et al., 1996). Entretanto, estes valores variam em condições de campo, dependendo da época do ano, hora do dia e fatores como condensação da água e aderência de poeira (Loy \& Wells, 1982; Hernández \& Morales, 1995; Hernández et al., 1996). Porém, todos esses fatores não devem limitar o crescimento das plantas se a radiação transmitida se encontra acima do ponto de saturação de fotossíntese das espécies cultivadas.

A radiação térmica dissipada na troca de calor sensível com a atmosfera constitui outro componente do balanço de energia. Este é quantificado mediante a variação da temperatura do ar. Para o PP, a temperatura diurna do ar pode aumentar até valores prejudiciais no início de crescimento do cultivo em conseqüência do efeito estufa. Entretanto, esse efeito pode ser amenizado pela troca gasosa entre o ambiente interno e externo devido à porosidade do PP. Além disto, a temperatura do ar sob a proteção diminui com o crescimento do cultivo devido à transpiração das plantas (Choukr-Allah et al., 1994; Hernández et al., 1996).

A radiação térmica consumida na troca de calor sensível com o solo representa um outro componente do balanço de energia. Este é caracterizado pela variação da temperatura do solo. Para uma determinada radiação líquida, esta variação será função do tipo e cor do solo, do conteúdo de umidade e especialmente, do grau de cobertura da cultura (Mansour \& Hemphill, 1987; Teasdale \& Abdul-Baki, 1995; Thomas \& Funkai, 1995).

Até o momento da realização do experimento, não foram encontrados na literatura publicações a respeito da potencialidade do uso do PP na região de Córdoba (Espanha), o qual poderia se apresentar como alternativa a mais para a agricultura da região. Em outros locais onde se testou o uso do PP como proteção de cultivo, foi constatada sua eficiência em adiantar e aumentar a produção, agregando qualidade aos produtos. Na região de Granada (Espanha), foi verificado aumento médio de $30 \%$ na biomassa de couve chinesa cultivada sob PP em relação ao cultivo em ambiente natural, durante a primavera de 1993 (Hernández et al., 1996). Já na região de Astúrias (Espanha) constatouse um aumento de 1,8 vezes na produção de alface cultivada sob PP em relação ao cultivo com "mulching", durante o período de inverno (Fuello et al., 1993). Em Agadir (Marrocos), os aumentos na temperatura mínima do ar foram de até $4,3^{\circ} \mathrm{C}$ ao longo do ciclo de Cucurbita pepo, com aumento de 59\% na produção total de frutos cultivados sob PP em relação à testemunha (Choukr-Allah et al., 1994).

No Brasil, o uso do PP como proteção de cultivo é praticamente desco- nhecido. A técnica tem sido utilizada na produção de mudas de fumo já há algum tempo (Buriol et al., 1996) e os primeiros resultados sobre o potencial do seu uso no cultivo de hortaliças foram avaliados na região Sul do país para alface (Otto et al., 1999), beterraba (Otto \& Reghin, 1999), mandioquinha-salsa (Reghin et al., 2000) e pimentão (Foltran et al., 1999).

O presente trabalho teve como objetivo caracterizar as modificações de parâmetros microclimáticos sob a proteção do "não tecido" de polipropileno, utilizado para o cultivo de couve-chinesa, alface, beterraba e espinafre, e as respostas produtivas das culturas, durante a primavera, outono e inverno de Córdoba, Sudeste da Espanha.

\section{MATERIAL E MÉTODOS}

O trabalho foi desenvolvido na área experimental do Centro de Investigación y Desarrollo Agrario, Córdoba, Espanha $\left(38^{\circ} \mathrm{N}, 5^{\circ} \mathrm{W}\right.$, altitude de $\left.110 \mathrm{~m}\right)$ durante os anos de 1995 e 1996. A região apresenta clima semi-árido, com temperatura média do mês mais quente acima de $28^{\circ} \mathrm{C}$, com $500 \mathrm{~mm}$ de precipitação anual. O inverno de 1995 foi especialmente chuvoso, com precipitações mensais acima de $200 \mathrm{~mm}$. Foram instalados quatro experimentos. O primeiro com couve-chinesa (Brassica pekinensis (Lour) Rupr.) 'Nagaoka 50', que foi transplantada em 22 de março de 1995 e colhida aos 69 dias depois do transplante (ddt). O segundo, com alface tipo Romana (Lactuca sativa var. longifolia Lam.) 'Fimana', foi transplantado em 16 de novembro de 1995 e colhido aos 111 ddt. A beterraba de mesa (Beta vulgaris L.) 'Plato de Egipto' e o espinafre (Spinacia oleracea L. ssp. glaba) 'Esmeralda', foram as espécies cultivadas no terceiro e quarto experimentos, semeadas em 13 de março e 11 de outubro de 1996, respectivamente. O espaçamento utilizado foi de $0,30 \times 0,30$ $\mathrm{m}$ para couve-chinesa e alface e de 0,25 x $0,30 \mathrm{~m}$ para beterraba e espinafre. As parcelas experimentais foram de 11,70 $\mathrm{x} 1,80 \mathrm{~m}$ para todas as culturas, exceto para couve-chinesa cuja dimensão foi de $11,70 \times 1,20 \mathrm{~m}$. Foram avaliados dois tratamentos em todos os experimentos, 


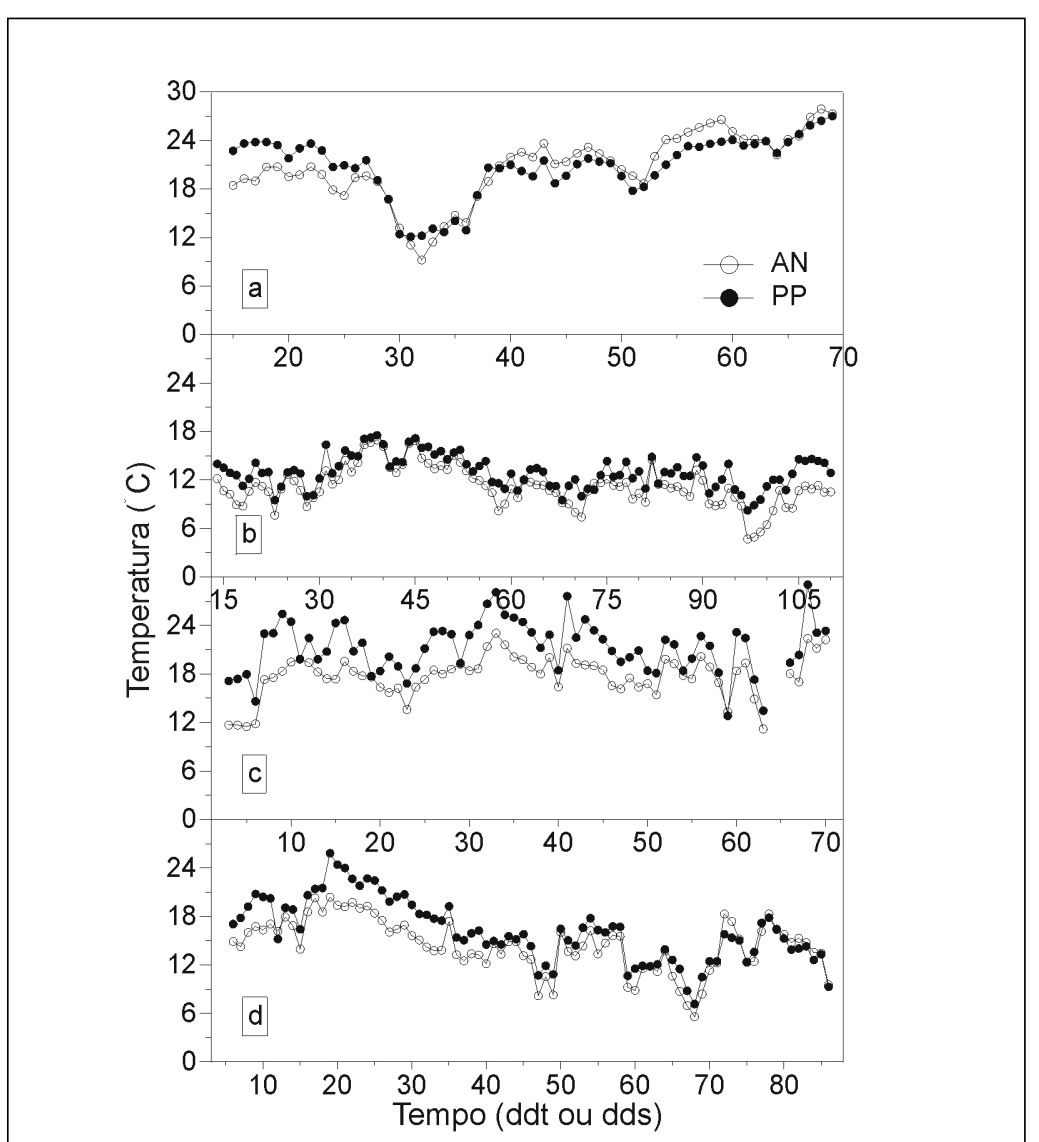

Figura 1. Temperatura média do ar ( $15 \mathrm{~cm}$ de altura do solo) para os tratamentos em ambiente natural (AN) e sob "não tecido" de polipropileno (PP) durante o ciclo das culturas de couve chinesa ( $\mathrm{a}$; ddt - dias depois do transplante), alface (b; ddt), beterraba (c; dds - dias depois da semeadura) e espinafre (d; dds). Córdoba, Espanha, Universidad de Córdoba. 1995/6.

sendo esses cultivos em ambiente natural (AN) e cultivo sob "não tecido" de polipropileno (PP) de 20-25 $\mathrm{mm}$ de espessura, 17 g.m. $\mathrm{m}^{-2}$. O delineamento experimental foi blocos ao acaso com quatro repetições, para cada um dos experimentos.

O solo é franco arenoso de origem aluvial, classificado como "Typic Xerofluvent", composto de $15,2 \%$ de argila, $14,1 \%$ de silte e $70,8 \%$ de areia. A adubação de base utilizada foi com a formulação 5-5-20, com $50 \mathrm{Kg}^{-1}$ de $\mathrm{N}$, $\mathrm{P}_{2} \mathrm{O}_{5}$ e $\mathrm{K}_{2} \mathrm{O}$ para couve chinesa, alface e beterrraba e de $90 \mathrm{Kg} \mathrm{ha}^{-1}$ de $\mathrm{N}, \mathrm{P}_{2} \mathrm{O}_{5} \mathrm{e}$ $\mathrm{K}_{2} \mathrm{O}$ para espinafre. A adubação de cobertura foi realizada aos $15 \mathrm{ddt}$, aplicando-se em média $2 \mathrm{~g}$ de N/planta. Em todos os experimentos foi utilizado o sistema de irrigação por gotejamento. $\mathrm{O}$ critério adotado para efetuar uma irrigação foi em função da umidade do solo dos sensores de temperatura (107, Campbell Scientific) e termopares (105T, Campbell Scientific) em cada parcela experimental. Todos os sensores de temperatura e de radiação foram conectados a um sistema de aquisição de dados (CR21X - Campbell Scientific), programado para realizar leituras a cada minuto e calcular médias a cada hora do dia, durante todo o período em que as espécies permaneceram no campo.

Para caracterização do crescimento e desenvolvimento das espécies foram realizadas colheitas periódicas durante os ciclos das espécies. Para couve-chinesa foram colhidas 4 plantas por parcela aos 26, 33, 43, 54, 63 e 69 ddt. Foi determinada a área foliar usando planímetro eletrônico (Licor 3000, LICOR). Estas plantas foram secadas em estufas com ventilação forçada a $70^{\circ} \mathrm{C}$ para obtenção do peso seco. O mesmo procedimento foi realizado para as culturas de alface, beterraba e espinafre aos 48, 64,81, 98 e $111 \mathrm{ddt}$, aos 36, 44, 56, $67 \mathrm{e} 71$ dias depois da semeadura (dds) e aos $28,44,58,72$ e 86 dds, respectivamente.

Com base nos valores de área foliar e peso seco de plantas individuais e considerando o espaçamento utilizado, foram calculados o índice de área foliar (IAF, $\mathrm{m}^{2} \mathrm{~m}^{-2}$ ), a biomassa total (BT, g. $\mathrm{m}^{-2}$ ) e a superfície foliar específica (SFE, $\mathrm{m}^{2} \cdot \mathrm{g}^{-1}$ ) para cada uma das amostras das espécies estudadas. A qualidade do limbo foliar foi caracterizada pela estimativa da SFE, onde valores maiores representam folhas de menor espessura e mais tenras. $\mathrm{Na}$ colheita final, foi medido o comprimento do caule da alface, após a retirada de todas as folhas, com um paquímetro e o pesos frescos da cabeça de couve chinesa e da raiz tuberosa da beterraba com auxilio de balança eletrônica.

As médias entre os tratamentos, para cada característica estudada e em cada cultura, foram comparadas mediante 0 teste de Tukey a $5 \%$ de probabilidade.

\section{RESULTADOS E DISCUSSÃO}

\section{Temperatura do ar $x$ produção}

A temperatura do ar sob proteção foi maior que em AN no início do ciclo de todas as culturas estudadas (Figura 1). 
Tabela 1. Índice de área foliar (IAF), Biomassa total da planta (BT; $\left.\mathrm{gm}^{-2}\right)$, Biomassa do produto comercial (BPC; $\left.\mathrm{gm}^{-2}\right)$ e superfície foliar específica (SFE; $\mathrm{cm}^{-2} \mathrm{~g}^{-1}$ ) de couve-chinesa, alface, beterraba e espinafre cultivados em ambiente natural (AN) e sob "não tecido" de polipropileno (PP) durante o ciclo das culturas. Córdoba, Espanha, Universidad de Córdoba. 1995/6.

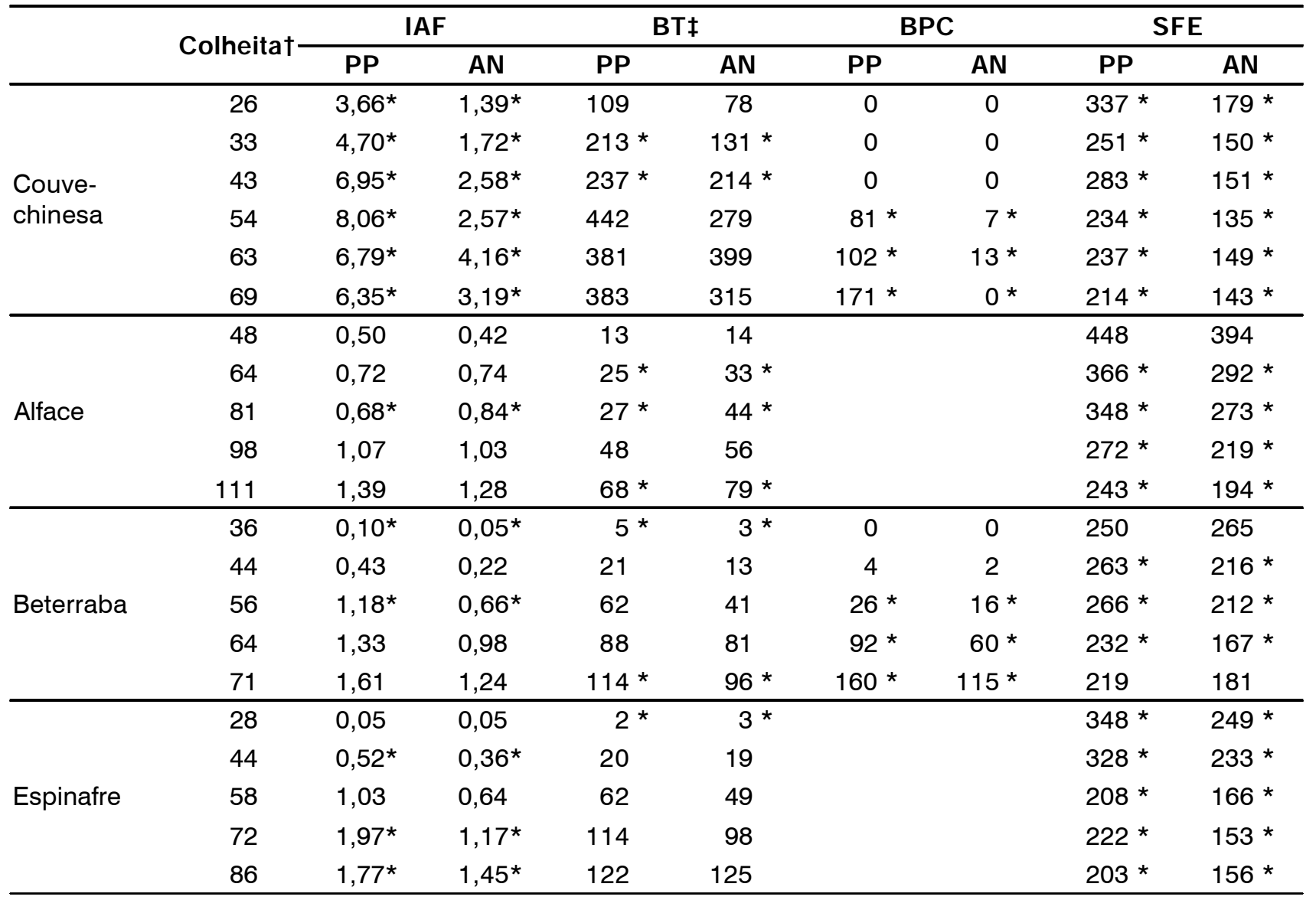

$\dagger$ 'Dias Depois do Transplante' para couve-chinesa e alface; 'Dias Depois da Semeadura'" para beterraba e espinafre.

\$ Para beterraba, é considerado somente a biomassa da parte aérea (não inclui o tubérculo)

* na horizontal, diferenças significativas entre tratamentos para teste de Tukey $(\mathrm{P}<5 \%)$

Com o passar dos dias, as diferenças de temperatura do ar entre o tratamento PP e AN diminuíram, chegando a valores similares (Figuras 1a, 1b, 1c) ou inclusive se invertendo (Figuras 1a, 1d). A intensidade destas modificações da temperatura do ar entre os dois ambientes dependeu da época do ano e do crescimento vegetativo da espécie cultivada.

As culturas de couve-chinesa e beterraba foram transplantadas no final do inverno, quando os valores de temperatura mínima do ar atingiram até 3,3 e $2,7^{\circ} \mathrm{C}$, respectivamente para cada espécie. Nesta época, a proteção permitiu que a temperatura média do ar fosse sempre maior que em AN (Figura 1), devido ao "efeito estufa". Para couve chinesa, as diferenças de temperatura entre PP e AN oscilaram entre 1,2 e $4,8^{\circ} \mathrm{C}$ entre 15 e $27 \mathrm{ddt}$, data em que a temperatura se igualou para ambos tra- tamentos (Figura 1a). Em beterraba, a temperatura do ar sob PP foi de 2 a $5,5^{\circ} \mathrm{C}$ maior que em $\mathrm{AN}$ durante os primeiros 30 dias de cultivo (Figura 1). Esse melhor regime térmico favoreceu ao crescimento inicial das plantas, representado pelos valores maiores de IAF sob PP em relação a AN (Tabela 1). O maior IAF sob PP garantiu, possivelmente, uma maior interceptação de radiação resultando em maior produção de biomassa total nesta fase inicial de crescimento (Tabela 1).

Com a aproximação dos dias de primavera, ocorre naturalmente um incremento nos valores da temperatura do ar. Entretanto, para a couve chinesa, a temperatura do ar sob PP tendeu a se igualar e chegou a ser menor que a temperatura do ar em condições naturais. Isto ocorreu possivelmente devido a modificação do balanço de energia devido ao crescimento da cultura. O maior IAF sob PP favoreceu a uma maior taxa de evapotranspiração (ET), diminuindo a temperatura do ambiente protegido. Em beterraba, o efeito não foi tão pronunciado como em couve chinesa devido aos menores valores de IAF produzidos durante o ciclo da cultura (Tabela 1).

Resultados semelhantes foram encontrados em Cucurbita pepo (Choukr-Allah et al., 1994) e em couve chinesa (Hernández et al., 1996) cultivadas sob PP, em Agadir (Marrocos) e em Granada (Espanha), respectivamente. As diferenças em temperaturas máximas entre PP e AN diminuíram progressivamente com $\mathrm{o}$ crescimento das culturas, chegando a inverter $(\mathrm{PP}<\mathrm{AN})$ após a metade dos ciclos.

No cultivo de outono (espinafre), as variações na temperatura do ar ao longo do ciclo foram similares às obtidas em couve chinesa e beterraba, onde as 


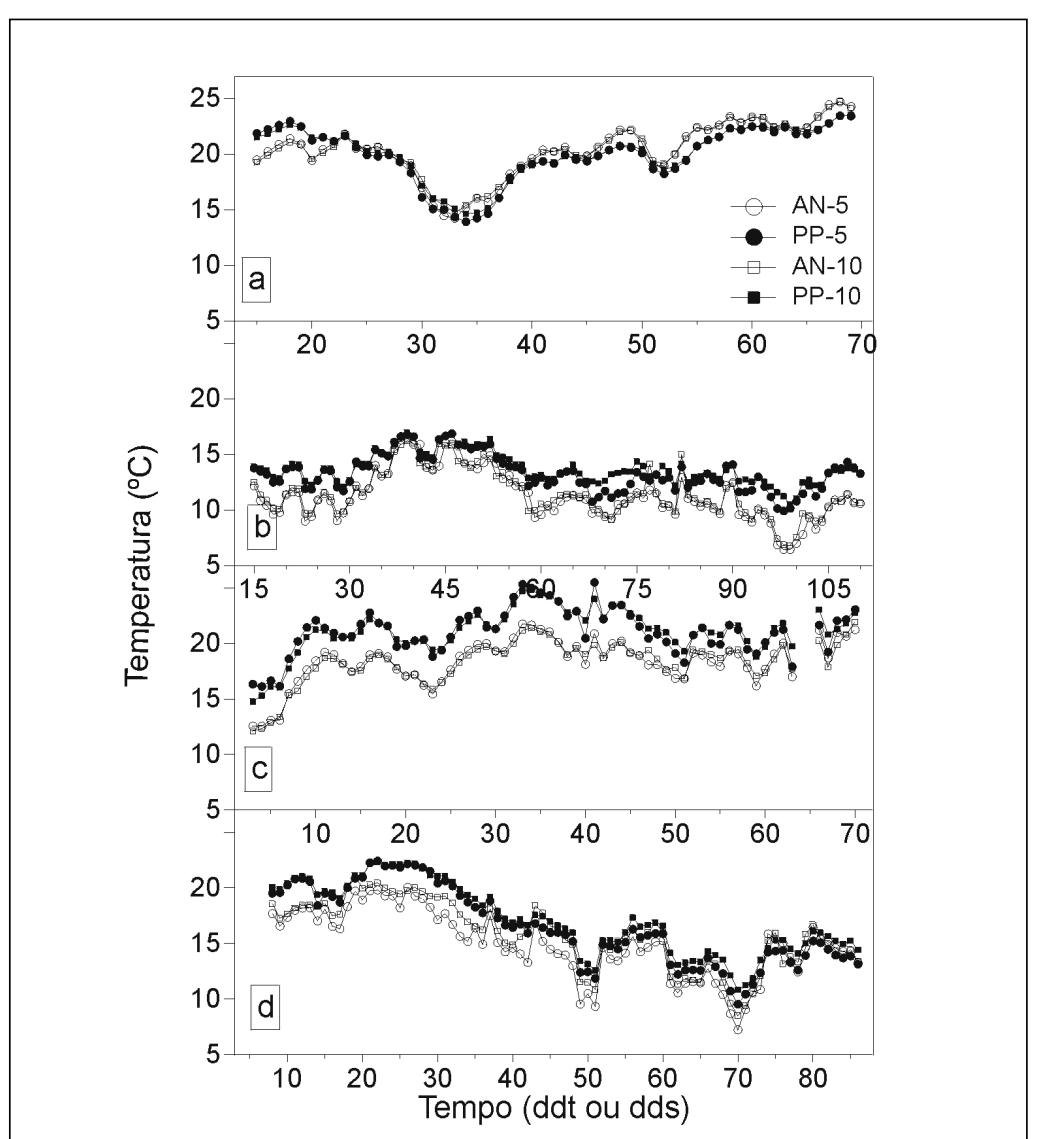

Figura 2. Temperatura média do solo a 5 e $10 \mathrm{~cm}$ de profundidade para o tratamento em ambiente natural (AN) e sob "não tecido" de polipropileno (PP) para as culturas da couvechinesa (a; ddt - dias depois do transplante), alface (b; ddt), beterraba (c; dds - dias depois da semeadura) e espinafre (d; dds). Córdoba, Espanha, Universidad de Córdoba. 1995/6.

diferenças de temperaturas médias entre PP e AN diminuíram com o tempo. As diferenças de temperatura mínima sob PP e AN foram menores que $1^{\circ} \mathrm{C}$ aos 30 dds, mostrando que o PP não reteve a radiação de onda longa apesar da condensação na parte inferior da proteção, comum durante este período. Aos 60 dias da semeadura, iniciou-se um período de chuvas que se prolongou até o final do ciclo, com dias nublados, resultando em valores menores de biomassa do espinafre em PP compara-

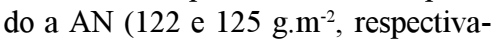
mente) (Tabela 1). Sob estas condições climáticas, é sugerido a retirada da proteção de polipropileno.

As mudas da alface foram transplantadas no final do outono e permaneceram no campo durante os meses de inverno. A temperatura média do ar foi sensivelmente maior sob PP que em AN caso, a temperatura do solo parece estar relacionada com o grau de cobertura do solo pela cultura (Mansour \& Hemphill, 1987; Teasdale \& Abdul-Baki, 1995; Thomas \& Funkai, 1995). Entretanto, as diferenças de temperatura do solo entre 5 e $10 \mathrm{~cm}$ de profundidade foram pouco significativas (médias de $0,5^{\circ} \mathrm{C}$ ) dentro de cada tratamento e para todas as culturas.

Em couve chinesa, a diferença máxima na temperatura do solo entre PP e AN foi de 2,4 e $2,2^{\circ} \mathrm{C}$ para 5 e $10 \mathrm{~cm}$ de profundidade, respectivamente, e ocorreu na fase inicial da cultura (15 ddt Figura 2a). Com o crescimento das plantas, as diferenças em temperatura do solo entre PP e AN para ambas profundidades se inverteram, apresentando diferenças de $-2,2^{\circ} \mathrm{C}$, a $5 \mathrm{~cm}$ de profundidade, entre PP e AN, aos 54 ddt. A cobertura total do solo não ocorreu em nenhum momento do ciclo da couve chinesa cultivada em ambiente natural (Tabela 1), o que permitiu o aumento da temperatura do solo em ambas profundidades, em relação ao ambiente protegido.

Por outro lado, as culturas de beterraba e espinafre não apresentaram um crescimento rápido da parte aérea como no caso da couve chinesa (valores menores de IAF), demorando mais tempo para cobrir a totalidade da superfície do solo cultivado sob PP. A beterraba apresentou diferenças máximas em temperatura do solo entre PP e AN de 4,1 e $3,9^{\circ} \mathrm{C}$ para 5 e $10 \mathrm{~cm}$ de profundidade, respectivamente, durante o início do ciclo. As diferenças entre PP e AN começaram a diminuir com o crescimento da cultura, ainda que não se inverteram em nenhum momento do ciclo (Figura 2).

Em espinafre, no início do ciclo, a diferença máxima de temperatura do solo entre PP e AN foi de 3,7 e $2,7^{\circ} \mathrm{C}$ para 5 e $10 \mathrm{~cm}$ de profundidade, respectivamente. Nos últimos 15 dias de cultivo, quando a cobertura do solo era total para ambos tratamentos, as diferenças médias entre PP e AN foram de $-0,6$ e $0,4^{\circ} \mathrm{C}$ para profundidades de $5 \mathrm{e}$ $10 \mathrm{~cm}$, respectivamente.

A cultura da alface foi transplantada no final do outono, época em que, além de baixas temperaturas do ar, ocorreram períodos de intensa precipitação 
(média de $200 \mathrm{~mm}$ mensais). Isto impediu o desenvolvimento normal das plantas, inclusive daquelas sob PP que permaneceram sob temperatura do ar superior a AN durante todo o ciclo (Figura 1b). Como a cobertura do solo não foi total em nenhum tratamento, as diferenças em temperatura do solo entre $\mathrm{PP}$ e AN se mantiveram durante todo o ciclo. Os valores máximos de diferença entre PP e AN $\left(3,8\right.$ e $4,3^{\circ} \mathrm{C}$ para 5 e 10 $\mathrm{cm}$, respectivamente) ocorreram no final do ciclo, quando a temperatura do ar em condições naturais começou a aumentar (final do inverno). Entretanto, nas fases intermediárias do ciclo, ocorreram diferenças mínimas de temperatura entre os tratamentos, isto é, 0,2 e $0,3^{\circ} \mathrm{C}$ para 5 e $10 \mathrm{~cm}$, respectivamente.

O aumento médio da temperatura do solo nos $10 \mathrm{~cm}$ superficiais do tratamento $\mathrm{PP}$ em relação a $\mathrm{AN}$ ao longo dos ciclos foi de $2,8,2,1$ e $1,4^{\circ} \mathrm{C}$ para beterraba, alface e espinafre, respectivamente. Entretanto, o uso do "não tecido" como proteção de couve-chinesa não aumentou a temperatura média do solo durante o ciclo desta espécie devido ao rápido crescimento da planta e à cobertura total do solo pela mesma.

$\mathrm{O}$ aumento da temperatura do solo devido ao uso da proteção de polipropileno foi verificado por outros autores (Soltani et al., 1995; Hernández et al., 1996). Teasdale \& Abdul-Baki (1995), trabalhando com "mulching" (polietileno preto) em tomate, verificaram que a temperatura do solo diminuiu com o crescimento do cultivo e sugeriram que o melhor regime térmico do solo sob o tratamento coberto, durante as quatro primeiras semanas da espécie, provavelmente contribuiu para a maior emergência e crescimento das raízes e maior precocidade do tomate em relação à testemunha. Thomas \& Funkai (1995), para estudos de diferentes tratamentos de umidade do solo em cevada e grão de bico, verificaram que as plantas sob estresse hídrico apresentaram pouco crescimento, não cobrindo a totalidade da superfície do solo. Isso permitiu o aumento da temperatura do solo, favorecendo o aumento da evaporação o que no final não contribuiu para o crescimento da cultura. Já o uso do "não tecido" como proteção de plantas resultou em melhor

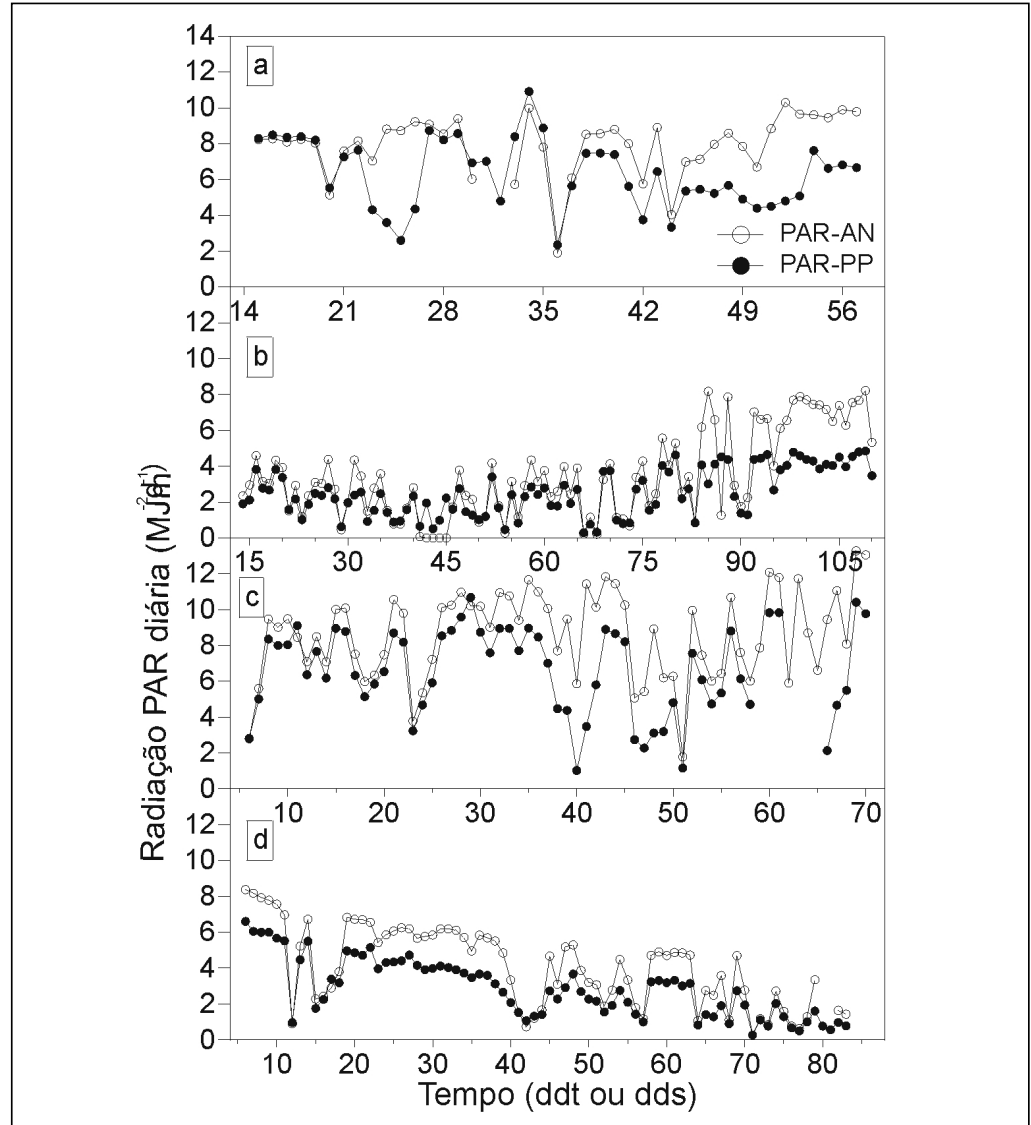

Figura 3. Radiação PAR diária (M5 $\left.\mathrm{m}^{-2} \mathrm{~d}^{-1}\right)$ sob "não tecido"de polipropileno (PP) e em ambiente natural (AN) durante o ciclo das culturas de couve-chinesa (a; ddt - dias depois do transplante), alface (b; ddt), beterraba (c; dds - dias depois da semeadura) e espinafre (d; dds). Córdoba, Espanha, Universidad de Córdoba. 1995/6.

condição hídrica do solo comparado ao cultivo em ambiente natural (Otto, 1997), o que juntamente com as modificações climáticas resultaram no maior crescimento de parte aérea das plantas.

\section{Radiação $x$ produção}

A relação entre a radiação incidente dentro e fora da cobertura representa a transmissividade do material utilizado. Esta variou entre 65 e $85 \%$, em função do tempo de uso do material e da época do ano.

Em geral, a transmissividade foi maior na fase inicial de crescimento das culturas, devido ao efeito do acúmulo de sujeira na superfície do "não tecido" com o passar do tempo. Na primavera, com ciclos de cultivo menores que nas épocas mais frias, a transmissividade diminuiu de $85 \%$ no começo do ciclo (Figura 3 a e 3 c) para $75 \%$ no final do ciclo
(Figura 3a). Entretanto, no outono-inverno, com ciclos superiores a 90 dias, a transmissividade do "não tecido" se reduziu de $80 \%$ no começo do ciclo (Figura $3 \mathrm{~b}$ ) para $65 \%$ no final do mesmo (Figura 3b e 3d).

A transmissividade do "não tecido" também variou segundo a época do ano, devido à menor elevação solar nos dias de outono-inverno em relação aos dias de primavera. Considerando valores para início de ciclo, a transmissividade variou entre 85 e $75 \%$ para dias de primavera e outono-inverno, respectivamente. Os valores baixos de radiação PAR sob PP em couve-chinesa entre os dias 104 e 107 foram devidos ao sombreamento do sensor por ervas daninhas.

A variação na transmissividade pode ocorrer desde que os valores de radiação incidente sob proteção não sejam 


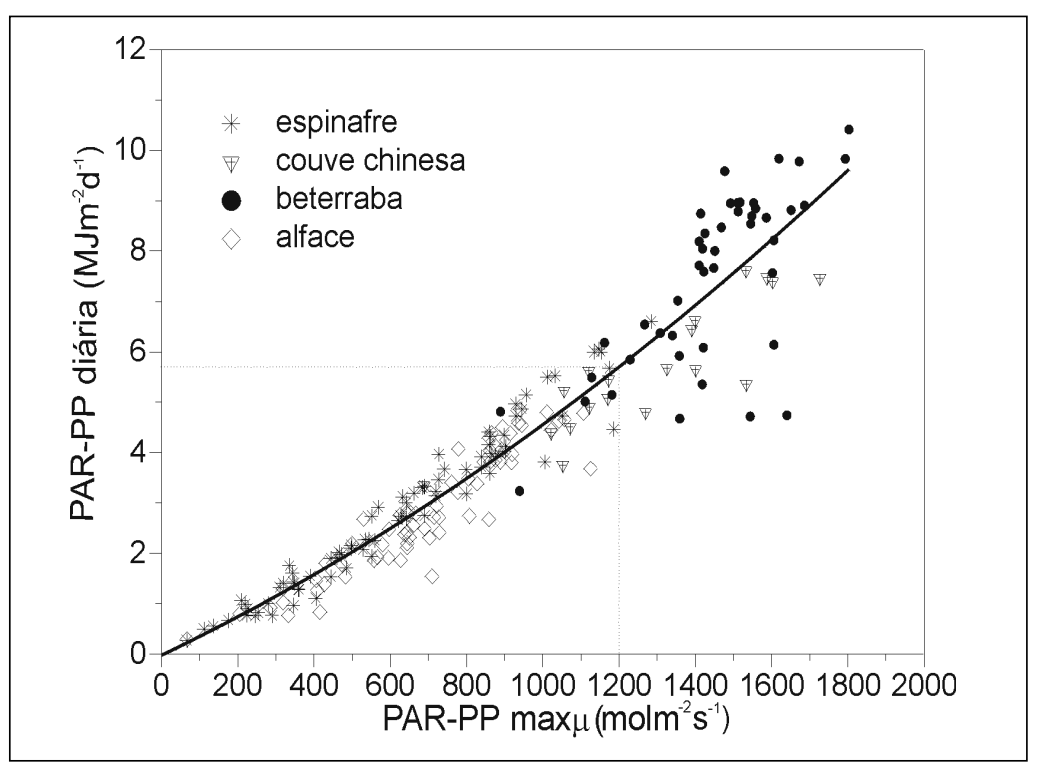

Figura 4. Radiação PAR diária (PP diária) e máxima (PP max) sob "não tecido" de polipropileno para as culturas de couve-chinesa, alface, beterraba e espinafre. Córdoba, Espanha, Universidad de Córdoba. 1995/6

limitantes ao desenvolvimento da cultura. Assim sendo, para se estimar o valor limite de radiação incidente, foi determinada a relação entre a integral diária de radiação PAR $\left(\mathrm{R}_{\mathrm{PAR}}\right)$ e a PAR máxima diária (PARmax), ambas sob o "não tecido", para todas as culturas (Figura 4), segundo a equação:

$$
\begin{aligned}
\mathrm{R}_{\mathrm{PAR}}= & -0,02045+0,00361(\mathrm{PARmax}) \\
& +9,641 \mathrm{e}^{-7}(\mathrm{PARmax})^{2}
\end{aligned}
$$

A relação estima um valor $R_{P A R}$ de 5,7 $\mathrm{MJm}^{-2} \mathrm{~d}^{-1}$ para um PARmax de 1200 mmolm ${ }^{-2} \mathrm{~s}^{-1}$, considerado como ponto médio de saturação de fotossíntese para a maioria das culturas hortícolas (Dr. Wolfe, D.W., comunicação pessoal). Com base nestes valores, as culturas de primavera (couve chinesa e beterraba) não apresentaram problemas de limitação de radiação sob proteção para a maioria dos dias do ciclo. Os níveis adequados de radiação, juntamente com as condições térmicas favoráveis resultaram em maior produção final (BPC) de couve chinesa e de beterraba para PP em relação a AN (Tabela 1) para ambas espécies. Nas plantas de couve chinesa cultivadas em ambiente natural ocorreu a emissão da haste floral, impedindo a formação da cabeça comercial. Ademais, o uso do "não tecido" aumentou a SFE das espécies (Tabela 1) de acordo com o documentado por Björkman (1981), como resposta a níveis mais baixos de radiação. Essa característica pode ser de especial importância para espécies hortícolas nas quais o produto comercial são as folhas, pois estas se apresentam mais tenras.

Da mesma maneira, as condições térmicas e de radiação favoráveis sob PP no início do outono, favoreceram um maior IAF da cultura de espinafre em relação às plantas cultivadas em ambiente natural (Tabela 1). Esse fato não só resultou em valores de biomassa sob PP ligeiramente superiores a AN (Tabela 1), como também contribuiu para produtos de maior qualidade, expressados em uma maior SFE (Tabela 1).

Entretanto, a cultura de inverno (alface) esteve submetida a níveis de radiação inferiores às necessidades ótimas da espécie durante a maior parte do ciclo para o tratamento PP (Figura 3). Isso foi devido à baixa elevação solar nesta época do ano e aos freqüentes dias nublados e chuvosos que diminuíram ainda mais a radiação incidente. Devido a isto, as plantas em PP apresentaram alongamento dos entrenós na colheita $(\mathrm{PP}=4,5 \mathrm{~cm}$ e $\mathrm{AN}=3,6 \mathrm{~cm}$ ), dificultando a formação da cabeça e produção de biomassa total sob PP em relação a AN (Tabela 1). Também, as folhas apresen- taram coloração verde muito clara e danos por abrasão, devido ao atrito do "não tecido" molhado com o limbo foliar. O resultado foi um produto sem valor comercial, ainda que o limbo foliar se apresentasse mais tenro sob PP em relação a AN > SFE, (Tabela 1).

A redução de $20 \%$ da radiação incidente devido ao uso do "não tecido" não prejudicou o crescimento das culturas em dias ensolarados, considerando que, nesta condição, os valores de radiação incidente excederam ao ponto de saturação de fotossíntese da maioria das espécies (Figura 4). Entretanto, nos dias nublados, a redução de $20 \%$ da radiação poderá impedir a saturação da taxa de fotossíntese das culturas, resultando em menor crescimento, ainda que tenha proporcionado um efeito favorável quanto a aumento de temperaturas do ar e do solo.

Pelos resultados obtidos conclui-se que a utilização do "não tecido" de polipropileno como proteção para culturas hortícolas aumenta as temperaturas do ar e do solo em relação ao ambiente natural, nas fases iniciais de crescimento das espécies. As diferenças entre as temperaturas sob proteção e ambiente natural tendem a se igualarem ou inclusive se inverterem com o crescimento das culturas.

O "não tecido" diminui a radiação incidente em média de $20 \%$ da total que chega sobre o material. Se esses valores sob PP estiverem abaixo de $5,7 \mathrm{MJm}^{-2} \mathrm{~d}^{-1}$, a proteção deve ser retirada para evitar que a cultura permaneça em condições de baixos níveis de radiação, diminuindo a produção final.

\section{LITERATURA CITADA}

ANDRADE JUNIOR, A.S. Manejo de irrigação na cultura da alface (Lactuca sativa L.) através do tanque classe A. Botucatu: UNESP, 1994. 103 p. (Tese mestrado).

BJÖRKMAN, O. Responses to different quantum flux densities. In: LANGE, O.L.; NOBEL, P.S.; OSMOND, C.B.; ZIEGLER, H. Physiological plant ecology I - Responses to the physical environment. New York: Springer-Verlag, 1981. p. 57 - 107.

BURIOL, G.L.; STRECK, N.A.; SCHNEIDER, F.M.; HELDWEIN, A.B. Temperature and moisture regime of a soil covered with transparent mulches. Revista Brasileira de Agrometeorologia, Santa Maria, v. 4, n. 2, p. 1 - 6, 1996. 
CHOUKR-ALLAH, R.; HAFIDI, B.; REYD, G.; HAMDY, A. Influence of non-woven on outdoor crops: Moroccan experience. In: INTERNACIONAL CONGRESS OF PLASTIC IN AGRICULTURE, 13, 1994, Verona, Italy. Proceedings... Verona: ICPA, 1994, 13 p.

FERNÁNDEZ, M.D.; ORGAZ, F.; VILLALOBOS, F; LÓPEZ-GÁLVEZ, J. Evaluación de métodos de cálculo de la evapotranspiración de referencia bajo condiciones de invernadero en Almería. Riegos y Drenajes XXI, v. 84, p. 35 - 39, 1995.

FOLTRAN, B.N.; OTTO, R.F.; REGHIN, M.Y. Uso da proteção de "não tecido" de polipropileno sobre a cultura do pimentão, em Ponta Grossa - PR. In: CONGRESSO BRASILEIRO DE OLERICULTURA, 39, 1999, Tubarão. Resumos ... Tubarão. SOB, 1999. Resumo n. 107.

FUELLO, M.A.O.; BARANDA, A.A.; ARRIETA, A.I. Semiforzado de lechuga con agrotextiles Producción de otoño-invierno al aire libre. Hortofruticultura, v. 4, p. 37 - 40, 1993.

HERNÁNDEZ, J.; MORALES, M.I. Los agrotextiles y sus aplicaciones. Hortofruticultura, v. 3, p. 45 - 47, 1995.

HERNÁNDEZ, J.; ROMERO, L.; CASTILLA, $\mathrm{N}$. Valoración agronómica y análisis microclimático de la técnica de semiprotección de cubiertas flotantes sobre col china. Granada, España: Universidad de Granada, 1996. $265 \mathrm{p}$.
LORENZO, P.M. Intercepcion de luz, bioproductividad e intercambio gaseoso durante la ontogenia del cultivo de pepino (Cucumis sativus L.) en invernadero. Almería, España: Junta de Andalucia, 1994. 255 p. Colección Monografias 17/96.

LOY, J.B.; WELLS, O.S. A comparison of slitted polyethylene and spunbonded polyester for plant row covers. HortScience, v. 17, n. 3, p. 405 - 407, 1982.

MANSOUR, N.S.; HEMPHILL JR., D.D. Bunching onion response to three floating row covers. HortScience, v. 22, n. 2, p. 318 - 319, 1987.

OTTO, R.F. Cubiertas de agrotextil em especies hortícolas: balances térmicos, evapotranspiración y respuestas productivas. Córdoba, España: Universidad de Córdoba, 1997. 157 p. (Tesis de doctorado).

OTTO, R.F.; REGHIN, M.Y. Respostas produtivas da beterraba cultivada sob "não tecido" de polipropileno durante o inverno de Ponta Grossa, PR. In: CONGRESSO BRASILEIRO DE OLERICULTURA, 39, 1999, Tubarão. Resumos ... Tubarão. SOB, 1999. Resumo n. 253.

OTTO, R.F.; REGHIN, M.Y.; SÁ, G.D. Efeito da proteção com "não tecido" de polipropileno sobre o desenvolvimento e produção de três cultivares de alface. CONGRESSO BRASILEIRO DE OLERICULTURA, 39, 1999, Tubarão. Resumos ... Tubarão. SOB, 1999. Resumo n. 251.
REGHIN, M.Y.; OTTO, R.F. SILVA, J.B.C "Stimulate Mo" e proteção com "Tecido Não Tecido" no pré-enraizamento de mudas de mandioquinha-salsa. Horticultura Brasileira, Brasília, v. 18, n. 1, p. 53-56, março, 2000.

SOLTANI, N.; ANDERSON, J.L.; HAMSON, A.R. Growth analysis of watermelon plants grown with mulches and rowcovers. Journal of the American Society for Horticultural Science, v. 120, n. 6, p. 1001 - 1009, 1995.

TEASDALE, J.R.; ABDUL-BAKI, A.A. Soil temperature and tomato growth associated with black polyethylene and hairy vetch mulches. Journal of the American Society for Horticultural Science, v. 120, n. 5, p. 848 853, 1995.

THOMAS; FUNKAI, S. Growth and yield response of barley and chickpea to water stress under three environments in Southeast Queensland. III. Water use efficiency, transpiration efficiency and soil evaporation. Australian Journal for Agriculture Research, v. 46, p. 49 - 60, 1995.

WELLS, O.S.; LOY, J.B. Intensive vegetable production with row covers. HortScience, $\mathrm{v}$. 20, n. 5, p. 822 - 826, 1985.

WOLFE, D.W.; ALBRIGHT, L.D.; WYLAND, J. Modeling row cover effects on microclimate and yield: I. Growth response of tomato and cucumber. Journal of the American Society for Horticultural Science, v. 114, n. 4, p. 562 $568,1989$. 